\title{
Embedded Generation Using Shared Solar
}

\author{
Eric AkpoviroroObar ${ }^{1 *}$, Abdelwahed Touati $^{1}$, and Nabila Rabbah ${ }^{1}$ \\ ${ }^{1}$ Laboratory of Structural Engineering, Intelligent Systems and Electrical Engineering ENSAM, Hassan II University Casablanca \\ Morocco
}

\begin{abstract}
The socio-economic development of a country (especially a developing one) is inextricably linked with the availability and affordability of electricity in that country. However most African countries have failed to bridge the gap between the demand and supply of electricity in their country owing either to the non-availability of power or the lack of synergy between the various disciplines that make up the power sector. Bedevilled with the current Covid-19 pandemic which ushers in the digital era of E-learning and virtual trade activities, Africa cannot afford to lag behind as a result of poor electricity supply. Our case study in this paper will be Africa's most populous country; Nigeria. We would look at the aged long practice of a centralized system of energy production which generates and transmits electricity over long distances ( thereby incurring colossal losses), the limitations of the National grid which covers only some parts of the country, the legal constraints, the resort to self-help by Nigerians who seek to produce their own electricity using generators that emit GHG which pollute the atmosphere and the economic implication of running generators, while proffering an eco-friendly solution in distributed or dispersed generation using Shared Solar Energy aimed at resolving the disparity between the demand and supply of Electricity. A solution which will invariably unlock economic growth especially during this Covid-19 pandemic.
\end{abstract}

\footnotetext{
*akposobar@yahoo.com
} 


\section{Introduction}

The most compound and extensive machine ever built by man is the electric grid. However, the central paradigm of electricity production is one with certain limitations. Limitations with regards conflicting policy objectives, resilience, reliability, security, expansion, economic and environmental exigences. These limitations are further inherent in the lives of about 1.2 billion people living without access to electricity, 600 million of which are from the African continent. With the African largest economy; Nigeria having an electrification rate of $54 \%[1]$ and which loses about 28 billion Dollars (10.1 trillion Naira) due to unreliable power [2] it is of paramount importance to reinforce and strengthen the existing centralized power architecture with shared solar energy using embedded generation so as to mitigate carbon dioxide emissions and feeder losses. Thereby saving investments costs on transmission and distribution networks.

\subsection{A Retrospecton The Power Sector From Inception.}

The Nigerian Electric Power Authority (NEPA) came into being after the amalgamation of the Electricity Corporation of Nigeria ECN (which was an act of parliament in the year 1951) and the Niger Dams Authority NDA (which was established in the year 1962) in 1972 [3]. NEPA was tasked with the responsibility of production, transmission and distribution of electricity to the lengths and breadths of Nigeria.

Unfortunately, the merger between the ECN and NDA which lasted from 1972 to 2005 did not address the poor service delivery of power to Nigerians. It is imperative to note that during the 33-year lifespan of NEPA, the regulation, policy formulation, operation and investment in the Nigerian power sector was the exclusive responsibility of the federal government of Nigeria (FGN).

The inefficiency in the power sector led the then President Olusegun Obasanjo to sign the Electrical Power Sector Reforms (EPSR) Act to law in 2005. As a result of which NEPA was renamed Power Holding Company of Nigeria (PHCN) and subsequently unbundled. The EPSR act made it possible to have private investors partner with the government in the production and distribution of energy. This led to the creation of six generation companies (GENCOs) and eleven distribution companies (DISCOs) with the Transmission Company of Nigeria (TCN) solely owned by the FGN. An independent regulator named the Nigerian Electricity regulatory commission (NERC) was also founded. It is also worthy of note that the GENCOs and DISCOs were given monopoly of their different zones.

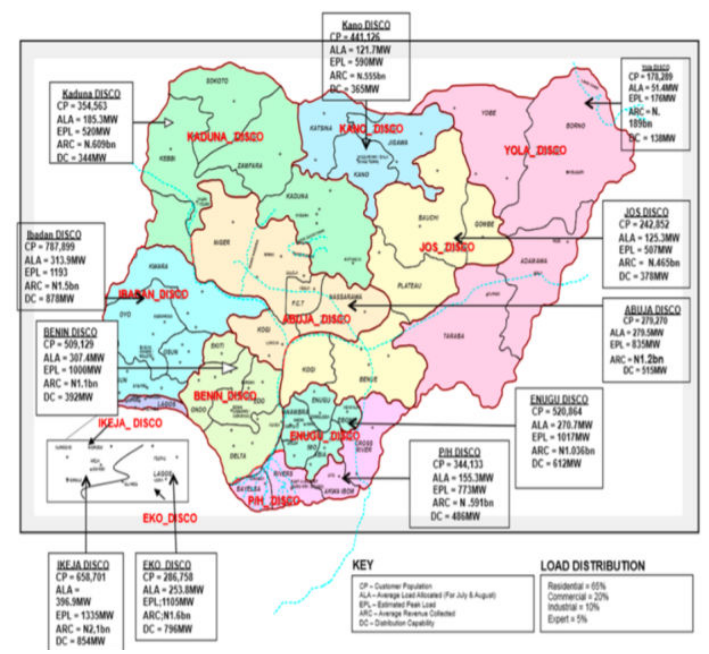

Fig. 1.DISCOs and their zones[7]

Unfortunately, years after the implementation of the EPSR act which was intended to revitalize the sector, the clear disparity between the demand and supply of electricity abounds with the total installed capacity of of about 12,522MW for 180 million Nigerians. What is more is that the National grid post privatization has in fact collapsed 108 times[4] The consequence being poor and erratic power supply.

\subsection{Challenges of the existing power Architecture}

The challenges of the power sector can be classified according to the various disciplines that make up the power sector. These disciplines include the following [5]:

\subsubsection{Engineering}

This discipline shoulders the responsibility of production, transmission and distribution of energy in a cost effective and efficient manner.

For the generation companies which are mostly gas fired and, in some cases located far from natural gas deposits, the problem of inadequate gas supply and vandalization of pipelines that supply gas to the various power plants abounds. Without forgetting infrastructural deficits for both the gas and hydro power plants.

The TCN suffers from inadequate grid/network coverage of the country. Infrastructural deficit which sometimes lead to system collapse (with the first collapse of this year being the $16^{\text {th }}$ January 2020[6]). Limitation in its ability to wheel the available capacity of the energy produced by the GENCOs and vandalization of transmission lines thereby contributing to the poor service delivery of energy to Nigerians.

The DISCOs also share the general problem of infrastructural deficit, inadequate network coverage of theirdifferent zones where they have monopoly and electricity theft on the part of consumers who do not pay their electricity bills. 


\subsubsection{Finance}

For the period of 33 years the FGN had the exclusive responsibility of financing and investing in the Nigerian power sector yet did very little. The financial implication of this neglect or dereliction of duty is the major reason for the infrastructural deficit in the power sector today. The EPSR Act gives the opportunity for private investors to make up for the financial aridity in the power sector. However, investors are still weary and prefer to stay aloof because of the uncertainty of the policies given by the regulatory body NERC[7].

\subsubsection{Management}

The management of human and material resources is of paramount importance for the success of any sector. The low morale of the National Union of Electricity Employees (NUEE) which led to an industrial action on the $11^{\text {th }}$ December 2019[8] should be permanently addressed. Workers must be well paid and have the certainty that after their many years of service in the power industry, they would have something to fall back to at their retirement.

The importance of the employee welfare cannot be overemphasized as they in turn are directly responsible for the maintenance and management of the equipment used, in the day to day activities of the power sector.

\subsubsection{Laws and Regulations}

Laws and regulations that act as bottle necks or hamper the evolution and progress of the power sector must be amended. The central method of production, transmission and distribution of electricity is no longer a viable option. At the generation level, not enough energy is produced to cater for needs of 180 million people. The transmission company of Nigeria is capable of wheeling a maximum of about 5300MW with the consumers receiving even lesser energy from the DISCOs. Furthermore, the transmission lines do not cover every part of Nigeria $(20,000 \mathrm{~km}$ of transmission lines) [9]

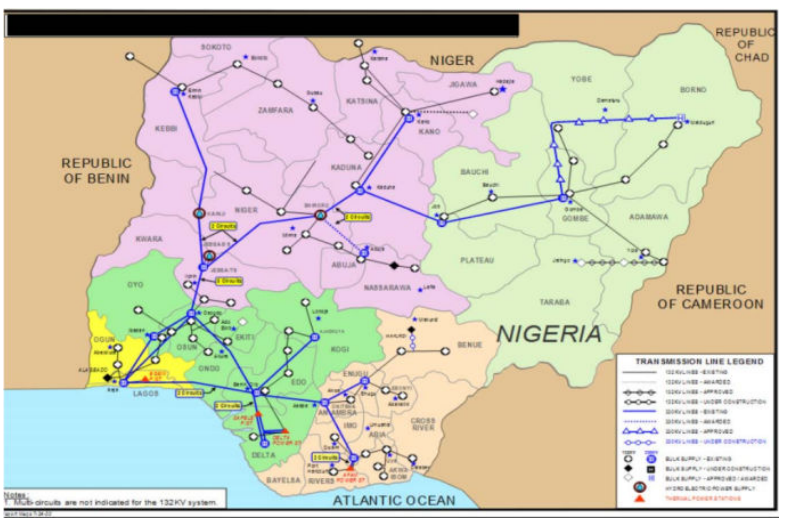

Fig. 2.Nigeria's transmission network[9]

\section{Environmental and economic implications of Using generators}

The two current methods of generating electricity on a large scale in Africa's most populous nation Nigeria are the use of hydro-electric power plants and the use of thermal power plants. Bearing in mind that of the $12,522 \mathrm{MW}$ installed capacity, $10,592 \mathrm{MW}$ is gotten from burning fossil fuels and the remaining 1,930MW by using hydro power plants[10].

The amount of carbon dioxide released to the atmosphere by the frequent burning of fossil fuels not only comes from generating power plants or automobile vehicles but also from the alarming resort to the generation of electricity with small scale petrol or diesel generators popularly known as "I better pass my neighbor." No wonder theinstalled capacity of decentralized dieselgenerators in Nigeria is said to be between 8 and 14GW[11].

From the survey data(secondary data) carried out on households spread across the 36 states and the Federal Capital territory by the Harmonized Nigeria Living Standards Survey(HNLSS 2009/2010)[12] and the use of the GHG protocol tool for stationary combustion[13], the GHG emissions resulting from the use of generators (in the residential sector) which operate on diesel and petrol in the thirty-six states of the Federal Republic of Nigeria are shown in the charts below. 


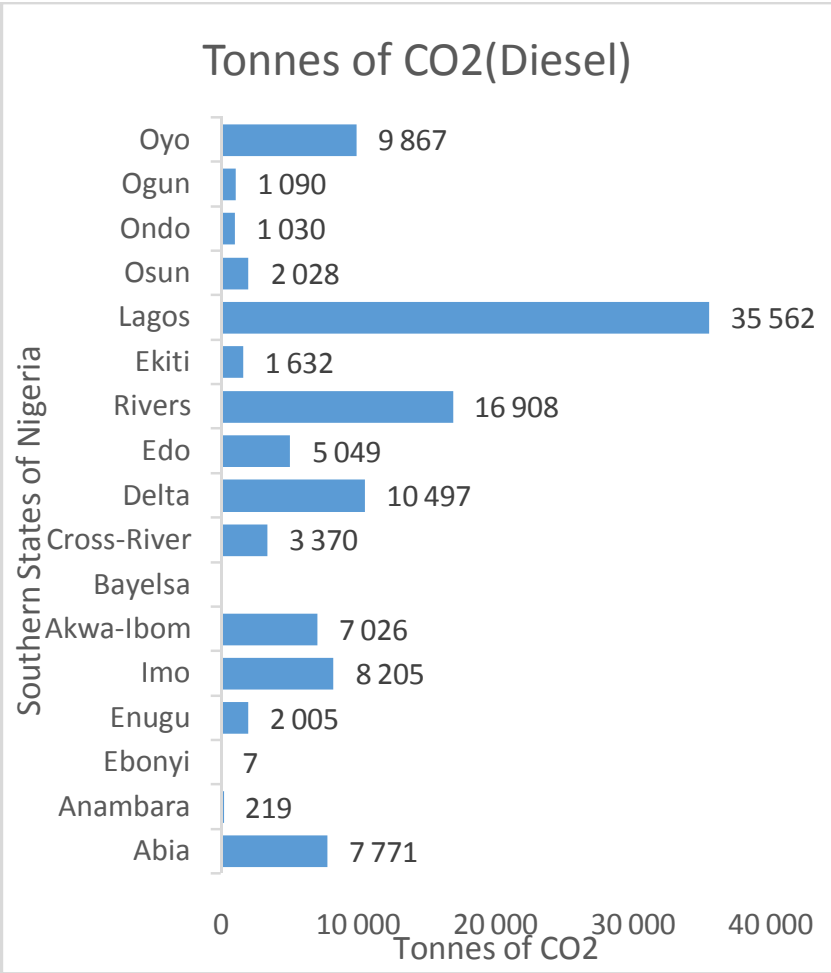

Fig. 3. Calculation of GHG emission of diesel generators in the southern states according to the HNLSS 2009/2010 survey data

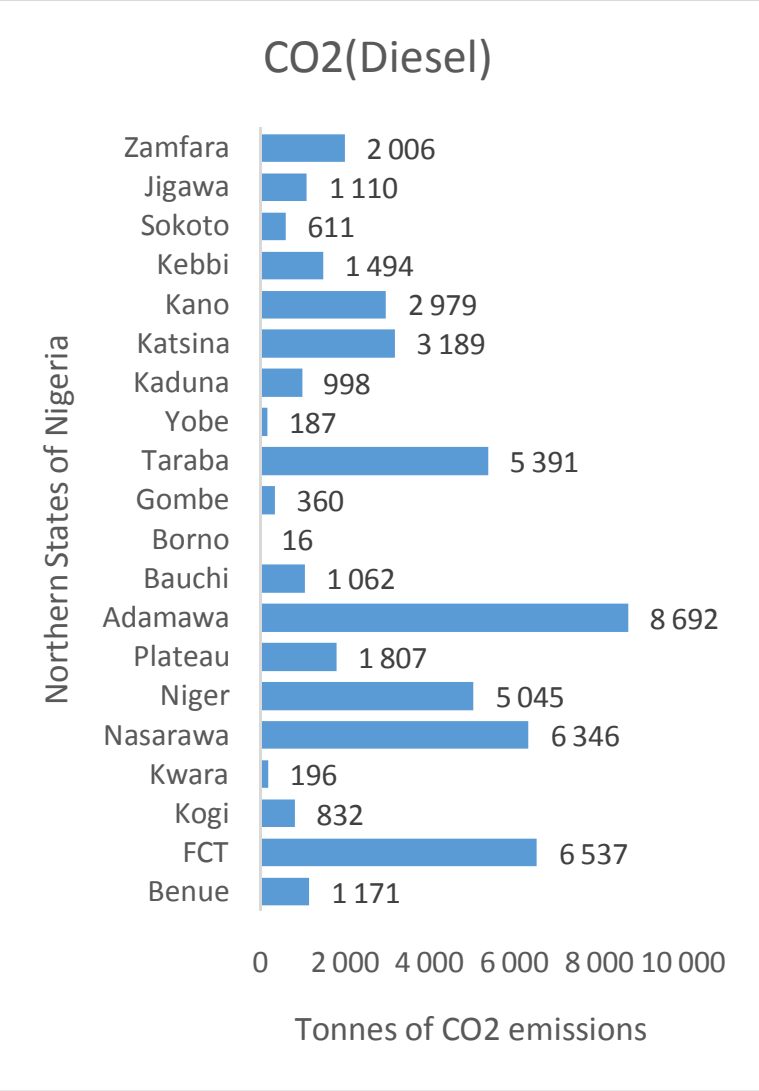

Fig. 4. Calculation of GHG emission of diesel generators in the Northern states according to the HNLSS 2009/2010 survey data

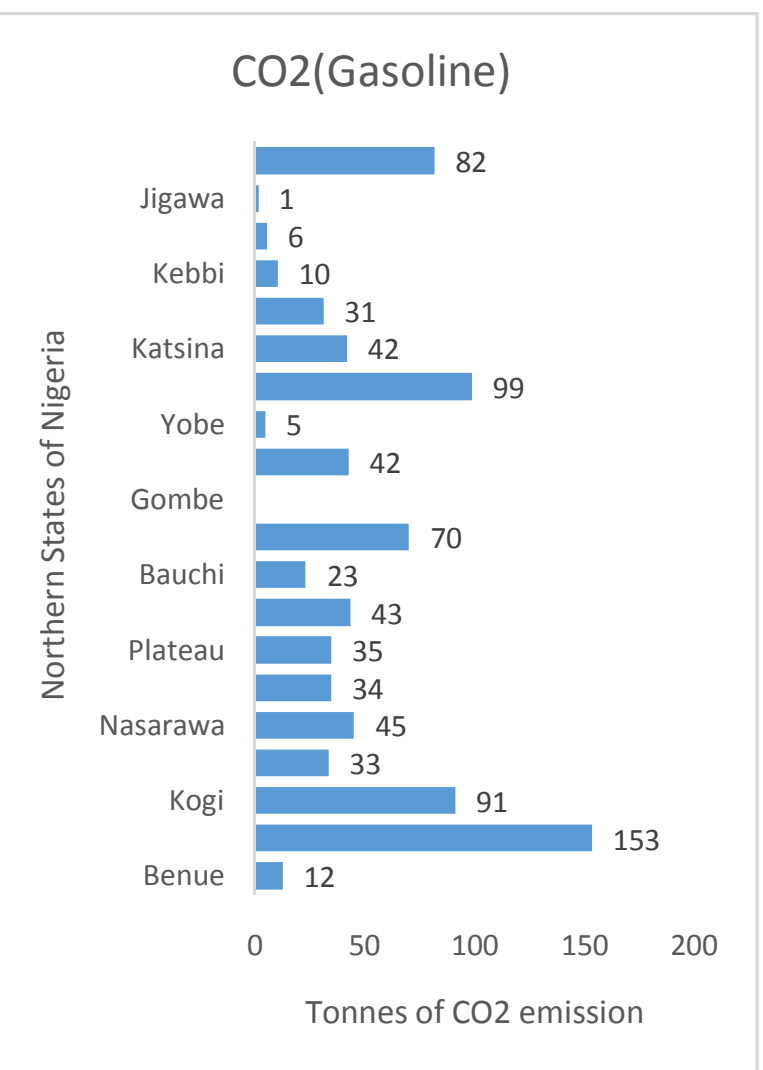

Fig. 5. Calculation of GHG emission of gasoline generators in the northern states according to the HNLSS 2009/2010 survey data

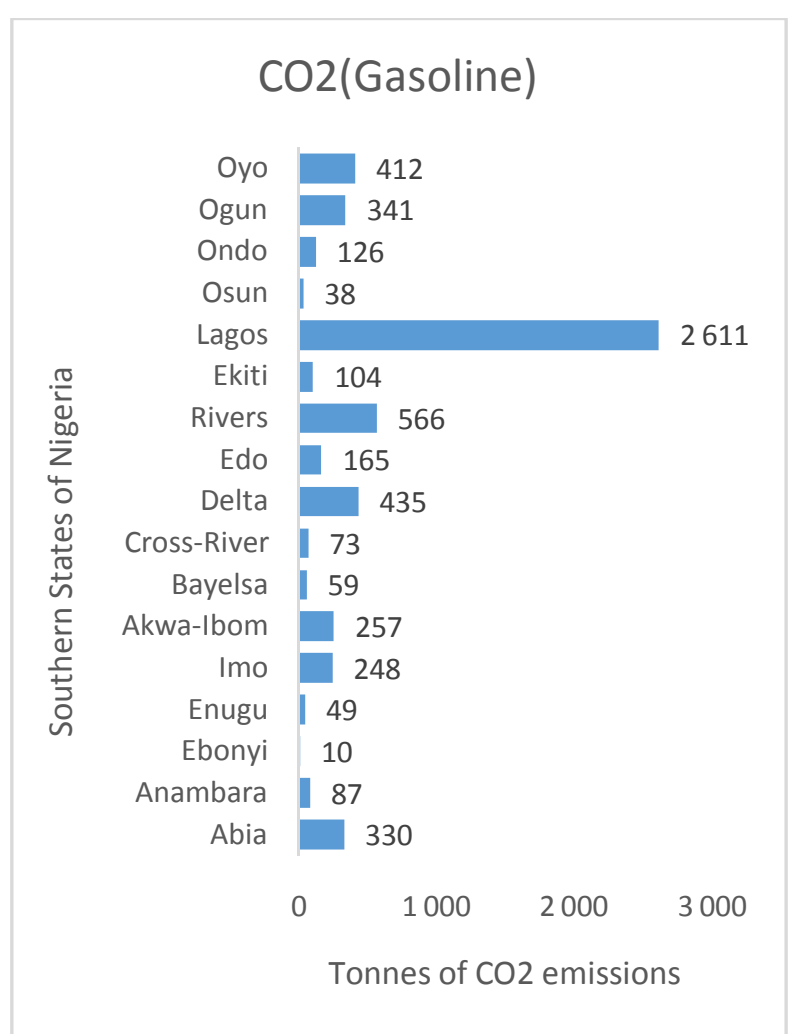

Fig. 6. Calculation of GHG emission of gasoline generators in the southern states according to the HNLSS 2009/2010 survey data 
The implication being an increase in environmental noise, the pollution of the atmosphere and the depletion of the ozone layer thereby contributing to global warming which in turn leads to climate change.

The economic implications of using generators for households according to data from the HNLSS 2009/2010[12] are shown in the table 1 below

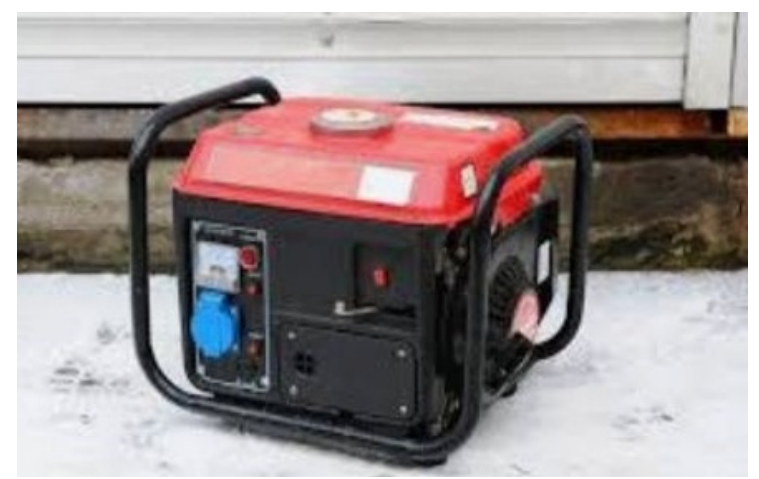

Fig. 7."I better pass my neighbour"[14]

Table 1.The economic implications of using generators for households according to data from the HNLSS 2009/2010[10]

\begin{tabular}{|l|l|c|l|}
\hline $\begin{array}{l}\text { Type of } \\
\text { fuel }\end{array}$ & $\begin{array}{l}\text { Number } \\
\text { of liters }\end{array}$ & $\begin{array}{l}\text { Price per } \\
\text { liter } \mathbf{( \$ )}\end{array}$ & $\begin{array}{l}\text { Total price } \\
\text { (\$) }\end{array}$ \\
\hline Diesel & $60,636,035$ & 0.582 & $35,290,172.37$ \\
\hline Gasoline & $2,978,840$ & 0.393 & $1,170,684.12$ \\
\hline
\end{tabular}

This result does not include the use of generators from other sectors of the economy like the Manufacturing sector, the Telecommunication sector, the Oil and Gas sector and the Commercial Sector.

\section{Embedded Generation using Shared Solar Energy}

Having looked at the challenges peculiar to the centralized power architecture of the Federal Republic of Nigeria, it is only fitting that one begins to think of a decentralized method of producing and distributing electricity in an effective and efficient manner so as to reinforce the already existing structure. The production of power within distribution networks close to the consumers is known as Embedded, decentralized or distributed Generation. Embedded generation can either be grid-tied or off the grid networks. Distributed generation can be achieved using Combined Heat and power (CHP) or Cogeneration units and Renewable Energy Sources (RES)[15].

Having talked about global air pollution, climate change, and the heavy reliance on generators in Nigeria to compensate for unreliable power supply, it is only logical that our approach or solution is one devoid of all the problems mentioned above; hence the concept of Shared Solar Energy.
Shared Solar Energy can be defined as "an arrangement where a group of individuals (often referred to as 'subscribers') lease or purchase solar panels or shares (kilowatts of capacity) in a neighborhood solar power installation"[16]. The energy gotten from the solar garden is used to power the homes or establishments of subscribers and may be fed to the national grid thereby making for the satisfaction of the energy demand of consumers and the reinforcement of the grid in cases of grid-tied installations.

This symbiotic relationship enables individuals who have land or roof top constraints to benefit from shared solar energy as though they had their own individual solar electrical installation. This innovative collaboration of individuals or cooperative financing of groups helps to achieve bulk pricing [16]and could easily meet the exponential national demand of electricity.

The concept of shared solar energy comes in 4 main forms namely[17]: Community Group purchasing, off-site shared solar, on-site shared solar and community-driven financial model.

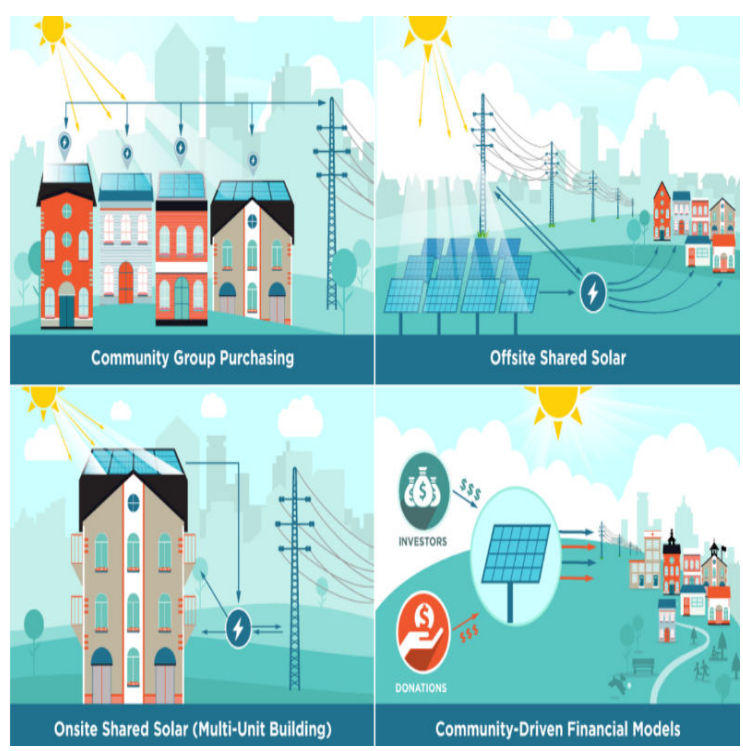

Fig. 8.Four main forms of shared solar energy [12].

\subsection{Stakeholders and Contractual Agreements.}

Aside having political proponents for the making and effectively implementing laws geared towards improving embedded generation through shared solar energy, it is imperative to state that private stakeholders play a major role for their agreements to be formal and legally binding. The possible stakeholders in this venture are as follows [18]:

1) Host site owner: is the owner of the property where the solar panels are installed. There is the possibility of having a site owner who isn't the owner of the solar electrical installation or a subscriber of shared solar energy.

2) The system owner: Owner of the solar electrical installation. 
3) The subscriber: An entity or individual with an electric bill who buys or leases shares in community solar agreement

4) Utility:The utility is an establishment that supplies or delivers electricity to consumers without necessarily going through the hurdles of generation. They are usually engaged for interconnection to the national grid.

5) Solar developer: A Solar Developer deals with the design of the electrical installation.

6) Solar installer: The solar installer takes care of the embedded generation unit. They may either be a development company or a third-party contractor.

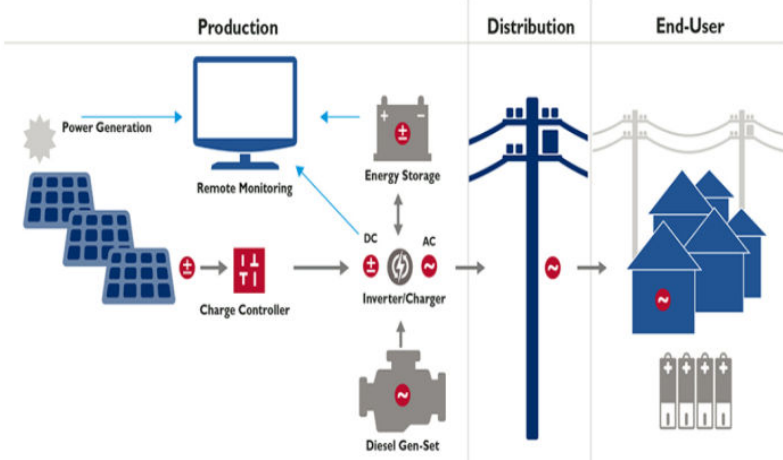

Fig. 9. Technical Components of a mini-grid [19]

7) Financial Institution: These are institutions that lend money of finance projects based on their financial model or business plan

8) Investor: Due to the capital-intensive nature of renewable energy investments, individuals or private investors are often required in solar development and installation to provide the capital necessary to finance the shared solar energy scheme. They usually require a return on investment of the system.

9) Foundation: They comprise of philanthropic organizations who fund solar development or provide incentives and technical assistance to solar developers.

10) Subscriber Management Organization:A thirdparty subscriber management organization is often hired to perform tasks like customer acquisition, billing and customer service for subscribers.

11) Community:refers to households, institutions and businesses in the immediate environment or site of the shared solar project.

A careful understanding of the interactions and contract agreements between the different stakeholders is of crucial importance for the success of the project. Some of the common contract agreements are [10]: The financing/loan agreement, lease agreement, subscriber agreement and the power purchase agreement

\subsection{Examples of Shared Solar Energy}

One of the major proponents of shared solar energy is the state of Colorado USA with the implementation of the Community Solar Garden's Act signed into law by Gov. Bill Ritter in 2010 which brought to life the Xcel Energy project (now generating about 28MW) and many other projects[20].

Another fascinating example of shared solar energy is the Harvard Solar Garden in Massachusetts which came into being to help the residents or businesses that were unable to participate in the solarize Mass program(a bid to increase the adoption of small scale solar electricity) in 2011 due to the heavy cost of individual installation, on site constraints(so much shade) and/or roof top constraints(the angle of inclination, weight constraints or no access to roof tops as is the case for renters)[21]. It now generates $500 \mathrm{KW}$ of solar energy and is fully subscribed to[16].

Another illustrative example of shared solar energy (an off-grid example) is in the town of Sirakorola in Mali where solar energy projects are mostly funded by the United Nations Development program (UNDP). Here the inhabitants contributed 10 percent of the total cost of production estimated at about 70000 dollars. Monthly subscriptions are also paid by beneficiaries for the technical maintenance of the electrical installations[22].

\section{Conclusion}

The radial structure of the Nigerian National grid should be reinforced with distributed or decentralized generation to increase the resilience and reliability of the grid. Embedded generation using shared solar energy will not only reduce transmission and feeder losses but also mitigate carbon dioxide emissions from generators that most Nigerians have turned to for reliable power.Thereby engaging in the production of green energy which is eco-friendly.

But this can only be achieved with the right laws and legislations from the regulating agency NERC. The government of Nigeria must do everything in its power to remove all the legal bottle necks that hamper the optimal production, transmission and distribution of electricity and replace them with policies that would make the power sector attractive for investors.

Furthermore, the result from table 1 and the world's bank estimation of 28 billion dollars (10.1 trillion Naira) loss[2] due to unreliable power are testament of the will of the Nigerian people to go the extra mile to get reliable power even at greater expense. Hence the viability of the energy market.

And finally, a reorientation of investors in generator importation and all those who benefit from the present architectural power setup with incentive compatibility is of paramount importance. 
[1] "Mapped: The 1.2 Billion People Without Access to Electricity - Visual Capitalist.” [Online]. Available: https://www.visualcapitalist.com/mapped-billion-peoplewithout-access-to-electricity/. [Accessed: 09-Nov-2020].

[2] "Nigeria to Keep the Lights on and Power its Economy." [Online]. Available: https://www.worldbank.org/en/news/pressrelease/2020/06/23/nigeria-to-keep-the-lights-on-andpower-its-economy. [Accessed: 10-Jul-2020].

[3] M. Oni, "Power sector Privatisation in Nigeria: Opportunities and challenges," J. Energy South. Africa, vol. 18 , no. 3, pp. 52-57, 2007.

[4] "Power grid has collapsed 108 times after privatisation TCN - Punch Newspapers." [Online]. Available: https://punchng.com/power-grid-has-collapsed-108-timesafter-privatisation-tcn/. [Accessed: 10-Jul-2020].

[5] Yemi Oke, "Conflicting laws keep Nigeria's electricity supply unreliable," THE CONVERSATION, 2017. [Online]. Available: https://theconversation.com/conflicting-laws-keepnigerias-electricity-supply-unreliable-81393. [Accessed: 30-Jan-2020].

[6] "Blackout as TCN suffers first system collapse in 2020." [Online]. Available: https://www.vanguardngr.com/2020/01/blackout-as-tcnsuffers-first-system-collapse-in-2020/. [Accessed: 11-Nov2020].

[7] H. O. E. and T. O. E. U.P. Onochie, "The Nigeria Electric Power Sector (Opportunities and Challenges)," $J$. Multidiscip. Eng. Sci. Technol., vol. 2, no. 4, pp. 494-502, 2015.

[8] "Just-In: Electricity workers begin nationwide strike | Nairametrics." [Online]. Available: https://nairametrics.com/2019/12/11/just-in-electricityworkers-begin-nationwide-strike/. [Accessed: 30-Jan2020].

[9] "Transmission." [Online]. Available: https://nerc.gov.ng/index.php/home/nesi/404-transmission. [Accessed: 30-Jan-2020].

[10] K. Oladipo, A. A. Felix, O. Bango, O. Chukwuemeka, and F. Olawale, "Power Sector Reform in Nigeria: Challenges and Solutions," IOP Conf. Ser. Mater. Sci. Eng., vol. 413, no. 1, pp. 1-13, 2018, doi: 10.1088/1757$899 X / 413 / 1 / 012037$.

[11] K. Ley, J. Gaines, and A. Ghatikar, "The Nigerian Energy Sector - an Overview with a Special Emphasis on a Special Emphasis on Renewable Energy, Energy Efficiency and Rurual Electrification," Int. Zusammenarbeit GmbH, no. June, 2015.

[12] “Diesel Power Generation,” Diesel Power Gener., 2014, doi: $10.1596 / 28419$

[13] "Calculation Tools $\mid$ Greenhouse Gas Protocol (Version 4.1)," World Resource Institute, 2015. [Online]. Available: https://ghgprotocol.org/calculation-tools. [Accessed: 10Jul-2020].

[14] "i better pass my neighbor generator - Google Search." [Online]. Available: https://www.google.com/search?q=i+better+pass+my+neig
hbor+generator\&rlz=1C1GCEB enMA881MA881\&sxsrf= ACYBGNSgBQnxsga2M22Bfd17OWix5PYytg:15804974 $65858 \&$ source $=1 \mathrm{nms} \&$ tbm $=i$ sch\&sa $=$ X\&ved $=2$ ahUKEwjjh JXww67nAhWEXRUIHYy8AHkQ_AUoAXoECA0QAw $\&$ biw $=1280 \&$ bih $=578 \#$ imgrc $=e c 4 y C x G v N O 9$ vhM. [Accessed: 31-Jan-2020].

[15] L. I. Dulau, "Optimization of a power system with distributed generation source," 2015 9th Int. Symp. Adv. Top. Electr. Eng. ATEE 2015, pp. 903-906, 2015, doi: 10.1109/ATEE.2015.7133930.

[16] E. A. Adadevoh, "Powering Africa through shared solar energy," Proc. - 2017 IEEE PES-IAS PowerAfrica Conf. Harnessing Energy, Inf. Commun. Technol. Afford. Electrif. Africa, PowerAfrica 2017, pp. 577-583, 2017, doi: 10.1109/PowerAfrica.2017.7991290.

[17] U.S. Department of Energy-Office of Energy Efficiency \& Renewable Energy, "Community and Shared Solar Department of Energy,” 2016. [Online]. Available: https://www.energy.gov/eere/solar/community-and-sharedsolar. [Accessed: 30-Jan-2020].

[18] C. County, C. Solar, and P. September, "Community Solar Case Study Overview," 2017.

[19] "What are the technical components of a mini-grid? | MiniGrids Support Toolkit | Energy | U.S. Agency for International Development." [Online]. Available: https://www.usaid.gov/energy/mini-grids/technicaldesign/components. [Accessed: 12-Jul-2020].

[20] D. Energy, R. Committee, and C. Schonhaut, "COLORADO LEADS THE WAY TO COMMUNITY SOLAR,” 2015.

[21] "Harvard Solar Garden." [Online]. Available: http://www.harvardsolar.org/. [Accessed: 31-Jan-2020].

[22] C. Assogba, "A Solar Revolution in West Africa's Villages," SciDev.Net, 2014. [Online]. Available: https://www.scidev.net/global/energy/feature/solarrevolution-west-africa-villages.html. [Accessed: 30-Jan2020]. 